\title{
Preparation of biologically active Arabidopsis ribosomes and comparison with yeast ribosomes for binding to a tRNA-mimic that enhances translation of plant plus-strand RNA viruses
}

\author{
Vera A. Stupina and Anne E. Simon* \\ Department of Cell Biology and Molecular Genetics, University of Maryland, College Park, MD, USA
}

\section{Edited by:}

K. Andrew White, York University, Canada

\section{Reviewed by:}

W. Allen Miller, lowa State University, USA

Lyuba A. Ryabova, Institute of Plant Molecular Biology, France

\section{*Correspondence:}

Anne E. Simon, Department of Cell Biology and Molecular Genetics, University of Maryland, College Park, MD 20742, USA e-mail:simona@umd.edu
Isolation of biologically active cell components from multicellular eukaryotic organisms often poses difficult challenges such as low yields and inability to retain the integrity and functionality of the purified compound. We previously identified a cap-independent translation enhancer $\left(3^{\prime} \mathrm{CITE}\right)$ in the $3^{\prime} \mathrm{UTR}$ of Turnip crinkle virus (TCV) that structurally mimics a tRNA and binds to yeast 80S ribosomes and 60S subunits in the P-site. Yeast ribosomes were used for these studies due to the lack of methods for isolation of plant ribosomes with high yields and integrity. To carry out studies with more natural components, a simple and efficient procedure has been developed for the isolation of large quantities of high quality ribosomes and ribosomal subunits from Arabidopsis thaliana protoplasts prepared from seed-derived callus tissue. Attempts to isolate high quality ribosomes from wheat germ, bean sprouts, and evacuolated protoplasts were unsuccessful. Addition of purified Arabidopsis 80S plant ribosomes to ribosome-depleted wheat germ lysates resulted in a greater than 1200-fold enhancement in in vitro translation of a luciferase reporter construct. The TCV $3^{\prime} \mathrm{CITE}$ bound to ribosomes with a three to sevenfold higher efficiency when using plant $80 \mathrm{~S}$ ribosomes compared with yeast ribosomes, indicating that this viral translational enhancer is adapted to interact more efficiently with host plant ribosomes.

\section{Keywords: plant ribosomes, TCV, $3^{\prime} \mathrm{CITE}, \mathrm{TSS}$, Arabidopsis thaliana protoplasts, virus translation}

\section{INTRODUCTION}

Studies of translation initiation using plant positive, singlestranded RNA viruses that lack a 5' 7-methyl guanosine cap have revealed a wide range of mechanisms centered on highly structured, $3^{\prime}$ proximal cap-independent translation enhancers ( $\left.3^{\prime} \mathrm{CITEs}\right)$ that bind to various host translation initiation factors (Simon and Miller, 2013). The $3^{\prime} \mathrm{CITE}$ of Turnip crinkle virus (TCV) is located in the $3^{\prime} \mathrm{UTR}$ and adopts an internal T-shaped structure (TSS) that topologically mimics a tRNA (McCormack et al., 2008) The TSS, formed from three hairpins and two pseudoknots, was shown to directly associate with yeast $80 \mathrm{~S}$ ribosomes and 605 ribosomal subunits with a binding preference for the P-site (Stupina et al., 2008). Yeast ribosomes were chosen for these initial studies due to the availability of simple, well-established, highly efficient purification methods (Meskauskas et al., 2005; Stupina et al., 2008; Leshin et al., 2011). In contrast, methods available for plant polysome preparations are complex and result in limited yields (Lax et al., 1986; Mustroph et al., 2009, 2013). Although eukaryotic ribosomal complexes are highly conserved, differences exist in the structure of yeast and plant ribosomes and in the composition of translation initiation factors (Malys and McCarthy, 2011). Due to these differences, binding kinetics and other biochemical analyses using yeast ribosomes and the TSS were cautiously interpreted.
Development of simple, efficient procedures for plant ribosome preparation must account for the large central vacuole in mature plant cells (up to $90 \%$ of the cell volume; Hara-Nishimura and Hatsugai, 2011), whose contents can cause significant degradation of ribosomes during lengthy purification procedures. The $\mathrm{pH}$ environment of the plant vacuole is acidic, and its contents are enriched with proteases and RNases. For example, plant RNS2, a ribonuclease that participates in the normal decay of rRNA, uses the vacuole as the final destination for rRNA degradation (MacIntosh and Bassham, 2011). In the absence of commercially available plant RNase inhibitors, procedures that are appropriate for yeast ribosome isolation must therefore be modified to reflect conditions that are specific to plant cells.

In this report, we describe a simple, efficient method for isolation of plant ribosomes and ribosomal subunits with high yield and quality from Arabidopsis thaliana protoplasts prepared from seed-derived callus tissue. Purified, salt-washed (sw) Arabidopsis ribosomes complemented ribosome-depleted wheat germ lysates (WGLs) and enhanced translation of a luciferase reporter construct by 1200 -fold, indicating high integrity and viability of the isolated ribosomes. Filter-binding assays demonstrated that a significantly higher percentage of purified Arabidopsis ribosomes associated with the TCV TSS compared with yeast ribosomes. These results indicate that the TCV 
TSS has evolved to maximize association with plant translation factors.

\section{MATERIALS AND METHODS PREPARATION OF SALT-WASHED 8OS RIBOSOMES FROM PLANTS}

For isolation of ribosomes from wheat germ (Kretschmer) and bean sprouts (fresh supermarket purchase), one volume of plant tissue was ground to powder in liquid nitrogen, resuspended in 5 volumes of plant buffer A [250 mM sucrose, $200 \mathrm{mM}$ Tris- $\mathrm{HCl}$ $\mathrm{pH} 8.8,30 \mathrm{mM} \mathrm{MgCl}_{2}, 50 \mathrm{mM} \mathrm{KCl}, 1 \mathrm{mM} \mathrm{DTT}$, and $1 \mathrm{mg} / \mathrm{ml}$ heparin], and cells lysed by incubation on ice for $5 \mathrm{~min}$. Cellular debris was removed by centrifuging the lysates in a microcentrifuge at $11,000 \mathrm{rpm}(10,000 \times \mathrm{g})$ for $1 \mathrm{~min}$ at $4^{\circ} \mathrm{C}$. For ribosome isolation from Arabidopsis thaliana protoplasts, sterilized seeds were plated on modified MS agar plates and grown into callus clumps as previously described in detail (McCormack and Simon, 2005). Approximately 1-2 ml of protoplasts and 3000-5000 pmol of ribosomes were obtained from $10 \mathrm{ml}$ of packed callus clumps. Freshly prepared protoplasts (McCormack and Simon, 2005) free from any remaining buffer were either frozen at $-80^{\circ} \mathrm{C}$ for storage of up to a year or directly used for ribosomes isolation. To generate evacuolated protoplasts, freshly prepared Arabidopsis protoplasts were subjected to ultracentrifugation through a $70-40 \%$ stepwise Percoll density gradient at 9,000 $\mathrm{rpm}(10,000 \times \mathrm{g})$ for $1 \mathrm{~h}$ at $25^{\circ} \mathrm{C}$ using an SW 40 Ti rotor to separate cells into fractions with and without vacuoles (Komoda et al., 2004). One volume of packed protoplasts or evacuolated protoplasts was gently resuspended in ice-cold two to five volumes of plant buffer A and left on ice for 5 min to complete cell lysis. Cellular debris were removed by centrifuging lysates in a microcentrifuge at 11,000 rpm for $1 \mathrm{~min}$ at $4^{\circ} \mathrm{C}$. To pellet $80 \mathrm{~S}$ ribosomes, supernatants were pooled and subjected to ultracentrifugation by layering $2.5 \mathrm{ml}$ of the supernatant over $2.5 \mathrm{ml}$ of plant cushion buffer [25\% glycerol, $500 \mathrm{mM}$ Tris$\mathrm{HCl} \mathrm{pH} 8.8,10 \mathrm{mM} \mathrm{MgCl}_{2}, 50 \mathrm{mM} \mathrm{KCl}, 1 \mathrm{mM}$ DTT, and $1 \mathrm{mg} / \mathrm{ml}$ heparin] in $5 \mathrm{ml}$ polyallomer centrifuge tubes $(13 \mathrm{~mm} \times 51 \mathrm{~mm}$, Beckman) followed by centrifugation at $4^{\circ} \mathrm{C}$ for $3 \mathrm{~h}$ at $50,000 \mathrm{rpm}$ $(268,000 \times g)$ using an MSL-50 rotor (Beckman). Alternatively, $6 \mathrm{ml}$ of supernatant were layered over $6 \mathrm{ml}$ of plant cushion buffer in $13 \mathrm{ml}$ polyallomer centrifuge tubes $(14 \mathrm{~mm} \times 95 \mathrm{~mm}$, Beckman) and centrifuged at $4^{\circ} \mathrm{C}$ for $20 \mathrm{~h}$ at $28,000 \mathrm{rpm}(139,000 \times \mathrm{g})$ using a SW-40 rotor (Beckman). Ribosome pellets were gently rinsed with storage buffer [25\% glycerol, $50 \mathrm{mM}$ HEPES-KOH $\mathrm{pH}$ 7.6, $\left.5 \mathrm{mM} \mathrm{Mg}\left(\mathrm{CH}_{3} \mathrm{COO}\right)_{2}, 50 \mathrm{mM} \mathrm{NH}_{4} \mathrm{Cl}, 1 \mathrm{mM} \mathrm{DTT}\right]$ and resuspended in the same buffer at a concentration of $2-7 \mathrm{pmol} / \mathrm{ml}$. Ribosome concentrations were based on OD readings at A260, where $\mathrm{A} 260=1$ is equivalent to 20 pmol of ribosomes (Meskauskas et al., 2005). At this stage, ribosome suspensions are referred to as " 1 st spin" ribosomes and can be stored at $-80^{\circ} \mathrm{C}$ for up to one year.

To remove any remaining ribosome-associated tRNAs, Arabidopsis ribosomes were treated as previously described for preparation of sw yeast ribosomes (Meskauskas et al., 2005). Specifically, 1st spin plant ribosomes were resuspended in $2.5 \mathrm{ml}$ of buffer $\mathrm{B}$ [10\% glycerol, $20 \mathrm{mM}$ Tris- $\mathrm{HCl} \mathrm{pH} 7.5,5 \mathrm{mM} \mathrm{Mg}\left(\mathrm{CH}_{3} \mathrm{COO}\right)_{2}$, $0.5 \mathrm{M} \mathrm{KCl}, 1 \mathrm{mg} / \mathrm{ml}$ heparin, and $1 \mathrm{mM} \mathrm{DTT}]$, GTP, and puromycin added to final concentrations of $1 \mathrm{mM}$, and the ribosome suspension incubated at $30^{\circ} \mathrm{C}$ for $30 \mathrm{~min}$. After dilution to a final volume of $6 \mathrm{ml}$ with buffer $\mathrm{B}$, the solution was layered over $6 \mathrm{ml}$ of buffer B cushion [25\% glycerol, $20 \mathrm{mM}$ Tris- $\mathrm{HCl} \mathrm{pH}$ 7.5, $5 \mathrm{mM} \mathrm{Mg}\left(\mathrm{CH}_{3} \mathrm{COO}\right)_{2}, 0.5 \mathrm{M} \mathrm{KCl}, 1 \mathrm{mg} / \mathrm{ml}$ heparin, and $1 \mathrm{mM}$ DTT] in a $13 \mathrm{ml}$ polyallomer centrifuge tube and subjected to centrifugation at $4^{\circ} \mathrm{C}$ for $20 \mathrm{~h}$ at $28,000 \mathrm{rpm}$ using an SW-40 rotor (Beckman). Salt-washed ribosome pellets were gently rinsed with storage buffer and resuspended in the same buffer at a concentration of 2-7 pmol/ml. Ribosomes have been stored at $-80^{\circ} \mathrm{C}$ for up to a year.

\section{PREPARATION OF 40S AND 60S RIBOSOMAL SUBUNITS}

$40 \mathrm{~S}$ and $60 \mathrm{~S}$ ribosomal subunits were isolated by subjecting 1st spin ribosomes to sucrose gradient centrifugation essentially as previously described for isolation of yeast ribosomal subunits (Stupina et al., 2008). 1st spin ribosomes were resuspended in $1 \mathrm{ml}$ buffer D [50 mM HEPES-KOH pH 7.6, 10 mM Mg(CH $\left.\mathrm{CH}_{3} \mathrm{COO}\right)_{2}$, $0.5 \mathrm{M} \mathrm{KCl}, 1 \mathrm{mg} / \mathrm{ml}$ heparin, and $2 \mathrm{mM} \mathrm{DTT}$. GTP and puromycin were added to final concentrations of $1 \mathrm{mM}$ and the ribosome suspension incubated at $30^{\circ} \mathrm{C}$ for $30 \mathrm{~min}$ to remove remaining tRNAs. The ribosome suspension was concentrated to $150 \mu \mathrm{l}$ using Amicon Ultra $(100 \mathrm{~K})$ columns (Millipore) and applied to a $12.5 \mathrm{ml}, 10-30 \%$ sucrose gradient prepared in buffer D and then subjected to centrifugation at $4^{\circ} \mathrm{C}$ for $18 \mathrm{~h}$ at $20,000 \mathrm{rpm}$ $(71,000 \times g)$ in a swinging bucket SW-40 rotor (Beckman). After centrifugation, the top $1.5 \mathrm{ml}$ of the gradient was discarded and the remaining material distributed into $0.5 \mathrm{ml}$ fractions. Four microliters of each fraction was loaded onto a 1.2\%, $0.5 \times$ TBE/agarose gel for detection of $40 \mathrm{~S} / 60 \mathrm{~S}$ subunits, and fractions containing the subunits combined into separate pools. The buffer was exchanged to $50 \mathrm{mM}$ HEPES-KOH pH 7.6, $5 \mathrm{mM} \mathrm{Mg}\left(\mathrm{CH}_{3} \mathrm{COO}\right)_{2}, 50 \mathrm{mM}$ $\mathrm{NH}_{4} \mathrm{Cl}, 10 \%$ glycerol, $1 \mathrm{mM}$ DTT, and the suspension concentrated by subjecting each pool to several rounds of centrifugation through Amicon Ultra (100 K) columns. After glycerol was added to a final concentration of $25 \%$, ribosomal subunits were stored at $-80^{\circ} \mathrm{C}$ for up to a year.

\section{RIBOSOME STABILITY ASSAYS}

Packed protoplasts $(20 \mathrm{ml})$ were re-suspended in either $100 \mathrm{ml}$ of yeast buffer A [10\% glycerol, 20 mM HEPES-KOH pH 7.6, $5 \mathrm{mM} \mathrm{Mg}\left(\mathrm{CH}_{3} \mathrm{COO}\right)_{2}, 50 \mathrm{mM} \mathrm{NH}_{4} \mathrm{Cl}, 1 \mathrm{mM} \mathrm{DTT}$, and $1 \mathrm{mg} / \mathrm{ml}$ heparin] or in $100 \mathrm{ml}$ of plant buffer A [250 mM sucrose, $200 \mathrm{mM}$ Tris- $\mathrm{HCl} \mathrm{pH} \mathrm{8.8,} 30 \mathrm{mM} \mathrm{MgCl}_{2}, 50 \mathrm{mM} \mathrm{KCl}, 1 \mathrm{mM}$ DTT, and $1 \mathrm{mg} / \mathrm{ml}$ heparin] and suspensions incubated at $4^{\circ} \mathrm{C}$ and $10^{\circ} \mathrm{C}$. Aliquots $(25 \mathrm{ml})$ were collected at 1,2 , and $4 \mathrm{~h}$ time points and total RNA extracted by bringing the aliquot volume to $300 \mathrm{ml}$ with water, addition of $300 \mathrm{ml}$ of phenol/chloroform [1:1] and ethanol precipitating the aqueous fraction. Purified RNA products were then resolved on a $1.2 \%, 0.5 \times$ TBE agarose gel.

\section{IN VITRO TRANSLATION USING RIBOSOME-DEPLETED WHEAT GERM LYSATES}

Commercially purchased WGL (Promega) was added to ultra-clear centrifuge tubes $(5 \mathrm{~mm} \times 41 \mathrm{~mm}$, Beckman $)$ and centrifuged at $40,000 \mathrm{rpm}$ for $5 \mathrm{~h}$ at $4^{\circ} \mathrm{C}$ using an MSL-50 rotor (Beckman). Supernatant containing depleted WGL was used for the in vitro translation assays. The ribosome pellet was re-suspended in storage buffer and analyzed by gel electrophoresis to approximate 
the amount of $80 \mathrm{~S}$ ribosomes removed from the lysate (approximately $0.5 \mathrm{pmol}$ of ribosomes were removed from each $10 \mu \mathrm{l}$ of WGL). In vitro translation assays (10 ml reactions) were performed according to the manufacturer (Promega), using $1.4 \mathrm{pmol}$ of luciferase reporter RNA. Two different reporters were tested: (1) uncapped firefly luciferase reporter RNA flanked by TCV $5^{\prime}$ UTR and $3^{\prime}$ sequences from position 3661 to the $3^{\prime}$ end at position 4054 ( $5^{\prime}$ UTR-Fluc-3661); and (2) capped and polyadenylated renilla reporter RNA (Cap-Rluc-A). The $5^{\prime}$ cap was added to the $5^{\prime}$ terminus of the renilla luciferase reporter by supplementing the in vitro transcription reaction with $\mathrm{m} 7 \mathrm{G}\left(5^{\prime}\right) \mathrm{ppp}\left(5^{\prime}\right) \mathrm{G}$ Cap analog (Ambion). The capped RNA was then polyadenylated with poly(A) Polymerase (New England Biolabs, NEB). To achieve $1 \times$ ribosome concentration, translation reactions were supplemented with 0.5 pmol of purified plant $80 \mathrm{~S}$ ribosomes, or $40 \mathrm{~S}$ and $60 \mathrm{~S}$ ribosomal subunits. Translation assays were incubated at $25^{\circ} \mathrm{C}$ for $90 \mathrm{~min}$ and then placed on ice. Luciferase activity was determined using a single-reporter assay system (Promega) and a Modulus Microplate Multimode Reader (Turner BioSystems).

\section{FILTER-BINDING ASSAYS}

Filter-binding assays were performed as previously described (Meskauskas et al., 2005). Ribosomes (15 pmol) and 1-60 pmol of $\left[{ }^{32} \mathrm{P}\right] 5^{\prime}$-end labeled TSS were combined in a total volume of $30 \mu \mathrm{l}$ in binding buffer [ $80 \mathrm{mM}$ Tris- $\mathrm{HCl} \mathrm{pH} \mathrm{7.4,} 160 \mathrm{mM} \mathrm{NH}_{4} \mathrm{Cl}$, $11 \mathrm{mM} \mathrm{Mg}\left(\mathrm{CH}_{3} \mathrm{COO}\right)_{2}, 6 \mathrm{mM} \beta$-mercaptoethanol, $0.4 \mathrm{mM} \mathrm{GTP}$, $2 \mathrm{mM}$ spermidine, $0.4 \mu \mathrm{g} / \mathrm{ml}$ of poly $(\mathrm{U})]$. Reactions were incubated for $30 \mathrm{~min}$ at $30^{\circ} \mathrm{C}$, loaded onto pre-moistened Millipore HA filters $(0.45 \mu)$, and subjected to vacuum filtration. Each filter was washed three times with $3 \mathrm{ml}$ of binding buffer and radioactivity quantified using a scintillation counter.

\section{RESULTS AND DISCUSSION}

\section{Arabidopsis PROTOPLASTS AS A SOURCE FOR PREPARATION OF PLANT RIBOSOMES AND THEIR SUBUNITS}

Analysis of associations between various types of molecules are often hindered by difficulties in purifying the molecules or molecular complexes. Until recently, yeast ribosomes have been used for studies on plant viral 3'CITEs that fold into tRNA-like structures because the biochemical properties of yeast ribosomes are wellcharacterized and the isolation procedures are relatively simple (Meskauskas et al., 2005; Leshin et al., 2011). Conducting such studies with more native materials requires isolation of plant ribosomes of good quality and in sufficient quantities, which is problematic due to the ease in which large vacuoles containing RNases and proteases are disrupted during the procedure.

To determine the most suitable plant source for isolation of high quality ribosomes, small-scale ribosome preparations were performed using wheat germ, bean sprouts, Arabidopsis protoplasts, and evacuolated Arabidopsis protoplasts, as described in the Section "Materials and Methods." Since commercially available RNase inhibitors do not inhibit plant RNases, plant buffer A used to lyse plant material contained elevated $\mathrm{pH}$ (8.8) and a high concentration of Tris- $\mathrm{HCl}$, conditions previously used for the isolation of plant polysomes (Davies and Larkins, 1973; Leaver and Dyer, 1974; Key et al., 1981). The quality of isolated ribosomes was determined by evaluating the integrity of ribosomal
(r)RNAs in situ following separation of ribosomes by gel electrophoresis.

Non-salt-washed ribosome preparations, termed 1st spin ribosomes, were judged as good quality from all plant sources with the exception of wheat germ (Figure 1A), which did not produce ribosomes of sufficient abundance for detection using this procedure (data not shown). Interestingly, samples of commercial WGL that were directly applied to the gels contained ribosomes of poor quality and thus this material was not subjected to the 1st spin isolation procedure (Figure 1A). Arabidopsis protoplasts produced significantly higher yields of 1st spin ribosomes than bean sprouts and evacuolated protoplasts, and thus were chosen as the source for a large-scale preparation. Starting with $1-2 \mathrm{ml}$ of packed protoplasts, 3000-5000 pmol of 1st spin ribosomes were isolated that were of equivalent quality as ribosomes isolated from small-scale preparations (Figure 1B, left panel). Ribosome preparations from both freshly prepared protoplasts and from protoplast pellets that were previously stored at $-80^{\circ} \mathrm{C}$ were of equivalent quality and yield.

To remove residual tRNAs from 1st spin ribosomes, plant ribosomes were salt-washed using a method previously developed for yeast ribosomes (Meskauskas et al., 2005). Gel-electrophoretic analysis of sw plant ribosomes indicated that the ribosomes maintained their integrity (Figure 1B, right panel). Since subsequent purification procedures that start with poor quality 1st spin ribosomes can result in further degradation of the ribosomes, the lack of detectable degradation of these sw ribosome preparations indicates that the initial purification procedure effectively removed detrimental enzymes. Isolation of $40 \mathrm{~S}$ and $60 \mathrm{~S}$ subunits from 1st spin ribosomes was performed using a previously described procedure for isolation of yeast ribosomal subunits (Stupina et al., 2008). Gel electrophoresis of fractions containing $40 \mathrm{~S}$ and $60 \mathrm{~S}$ subunits displayed well-separated subunits that did not show any detectable degradation (Figure 1C). Fractions containing the individual subunits were combined and subjected to centrifugation through Amicon Ultra columns to exchange the buffer and to concentrate the subunits (Figure 1C, right panel).

\section{RNA STABILITY ASSAYS: PLANT BUFFER A PROVIDES A MORE STABLE ENVIRONMENT DURING RIBOSOMAL PURIFICATION COMPARED WITH YEAST BUFFER A}

RNA stability assays were conducted to determine if plant buffer A provides a more stable environment for plant ribosomes during the cell lysis step compared with the buffer used for yeast ribosome isolation (yeast buffer A; Meskauskas et al., 2005). Frozen protoplast pellets were resuspended in either yeast buffer A [10\% glycerol, $20 \mathrm{mM}$ HEPES-KOH pH 7.6, $5 \mathrm{mM} \mathrm{Mg}\left(\mathrm{CH}_{3} \mathrm{COO}\right)_{2}$, $50 \mathrm{mM} \mathrm{NH}{ }_{4} \mathrm{Cl}, 1 \mathrm{mM}$ DTT, and $1 \mathrm{mg} / \mathrm{ml}$ heparin] or plant buffer A [250 mM sucrose, $200 \mathrm{mM}$ Tris- $\mathrm{HCl} \mathrm{pH} 8.8,30 \mathrm{mM}$ $\mathrm{MgCl}_{2}, 50 \mathrm{mM} \mathrm{KCl}, 1 \mathrm{mM} \mathrm{DTT}$, and $1 \mathrm{mg} / \mathrm{ml}$ heparin] and suspensions incubated for up to 4 h at 4 and $10^{\circ} \mathrm{C}$. Total RNA isolated from samples removed at various time points were inspected for integrity on agarose gels (Figure 2). No visible degradation of the rRNA was observed after $4 \mathrm{~h}$ incubation at $4^{\circ} \mathrm{C}$ in plant buffer $\mathrm{A}$ and only minimal degradation was present at $10^{\circ} \mathrm{C}$ (Figure 2). In contrast, RNA cleavage products were visible after 


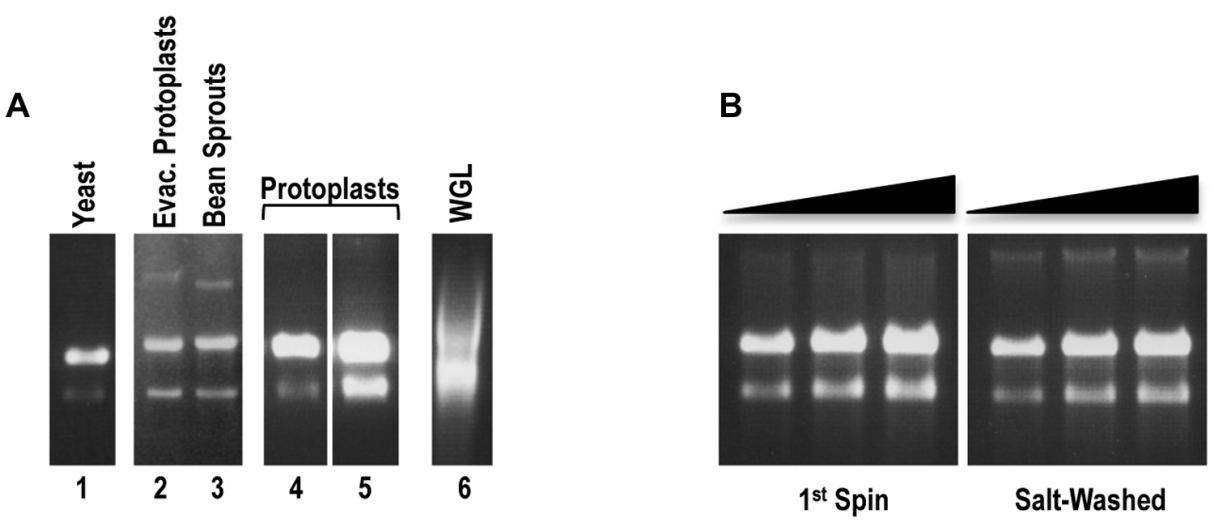

C



FIGURE 1 | Arabidopsis protoplasts serve as the optimal source for the preparation of plant ribosomes and their subunits. (A) In situ RNA gel electrophoresis analysis of small-scale ribosomal preparations (1st spin) from evacuolated Arabidopsis protoplast extracts (lane 2), bean sprouts (lane 3), Arabidopsis protoplasts (preparations 1 and 2, lanes 4 and 5). Yeast ribosomal preparation (lane 1) and aliquot of commercial WGL (Promega; lane 6) served as controls. Each preparation ( $1 \mathrm{ml}$, between 2.5 and 5 pmol of ribosomes) was resuspended in an equal volume of $100 \%$ formamide and the mixture directly loaded onto a $1.2 \%, 0.5 \times$ TBE agarose gel. rRNA was detected by staining gel with ethidium bromide. Note that although $80 \mathrm{~S}$ ribosomes were loaded, the ribosome subunits disengage in the gel and thus the large and small rRNAs become separated. (B) In situ RNA gel electrophoresis analysis of the large-scale plant ribosomal preparation from Arabidopsis protoplasts: $80 S 1$ st spin (left panel) and sw 80 S (right panel). Three different concentrations $(0.5,0.75,1 \mathrm{pmol})$ were loaded for each panel.

(C) Sucrose-gradient separation of plant $40 \mathrm{~S}$ and $60 \mathrm{~S}$ ribosomal subunits. After centrifugation, the first $1.5 \mathrm{ml}$ of the gradient were removed from the top of the tube and discarded. The remaining sucrose gradient containing subunits was subdivided into $0.5 \mathrm{ml}$ fractions. Each fraction $(4 \mathrm{ml})$ was resolved on a $1.2 \%, 0.5 \times$ TBE agarose gel for detection of rRNA from $40 \mathrm{~S}$ and $60 S$ subunits in situ (left panel). Fractions containing $40 \mathrm{~S}$ and $60 \mathrm{~S}$ subunits were combined into two pools. After buffer exchange and sample concentration, $2 \mu \mathrm{l}$ of each pool were loaded onto the agarose gel to inspect the quality of the rRNA (right panel).

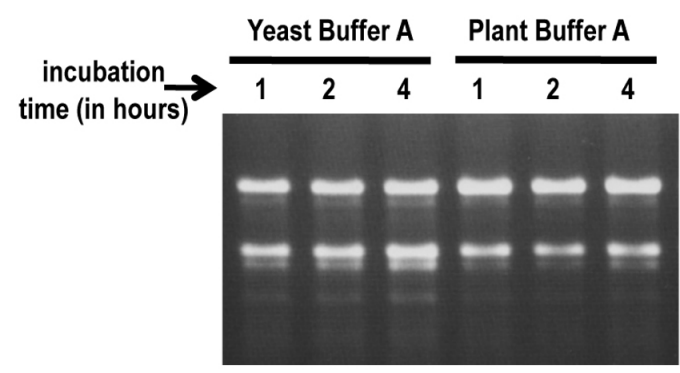

$4^{\circ} \mathrm{C}$

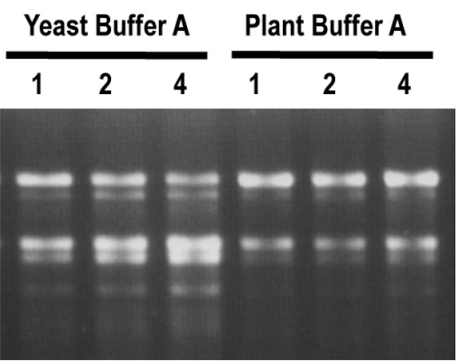

$10^{\circ} \mathrm{C}$

FIGURE 2 | RNA stability assays. Frozen protoplast pellets were re-suspended in either yeast buffer A or plant buffer A. Suspensions were incubated at either $4^{\circ} \mathrm{C}$ (left panel) or $10^{\circ} \mathrm{C}$ (right panel). Aliquots were taken at 1,2 , and $4 \mathrm{~h}$ time points to extract rRNA. RNA ( $\left.1 \mu \mathrm{g}\right)$ was inspected for integrity on $1.2 \%, 0.5 \times \mathrm{TBE}$ agarose gels.

$4 \mathrm{~h}$ incubation in yeast buffer $\mathrm{A}$ at $4^{\circ} \mathrm{C}$ and degradation was significantly increased when the temperature was raised to $10^{\circ} \mathrm{C}$. This suggests that the higher $\mathrm{pH}$ and elevated concentration of Tris$\mathrm{HCl}$ in plant buffer A inhibits degradation enzymes and thus helps to maintain the integrity of the ribosomes during the isolation process.

\section{SALT-WASHED PLANT RIBOSOMES ARE FUNCTIONAL IN RIBOSOME-DEPLETED WGL FOR TRANSLATION OF A LUCIFERASE REPORTER mRNA}

Purified plant ribosomes were tested for functionality in ribosomedepleted WGL (Figure 3) using luciferase reporter construct 5'UTR-Fluc-3661, which was previously used to detect synergy 
A

5'UTR-Fluc-3661
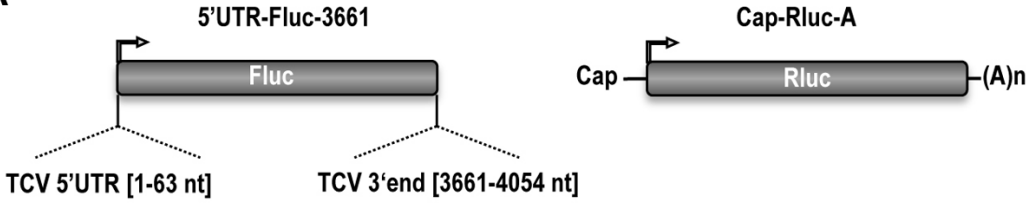

B

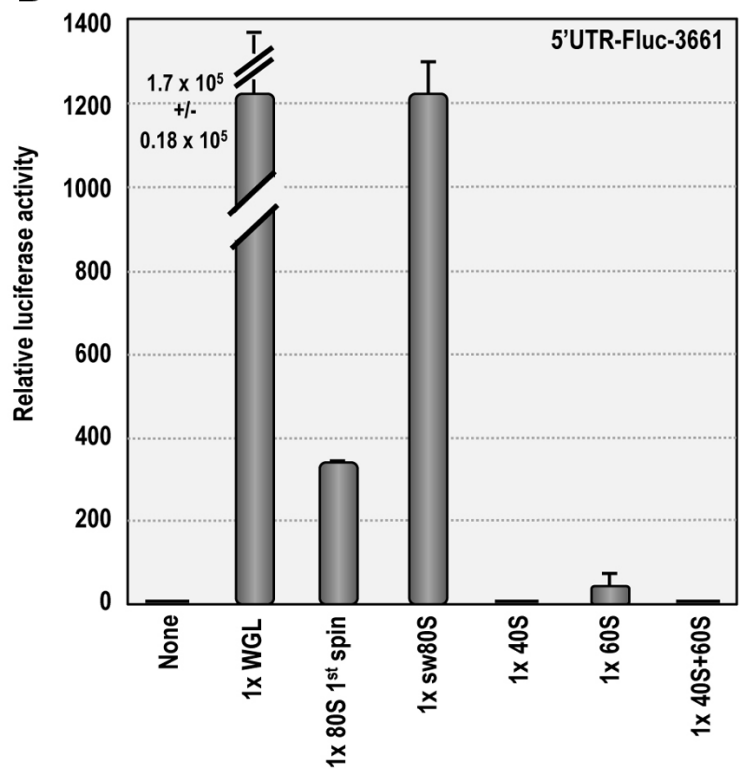

C

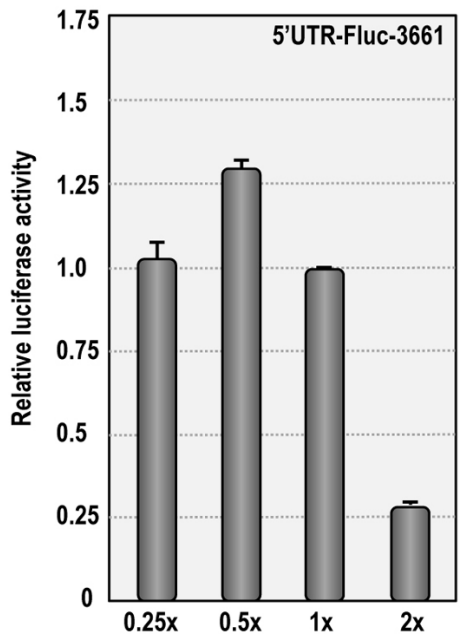

D

E
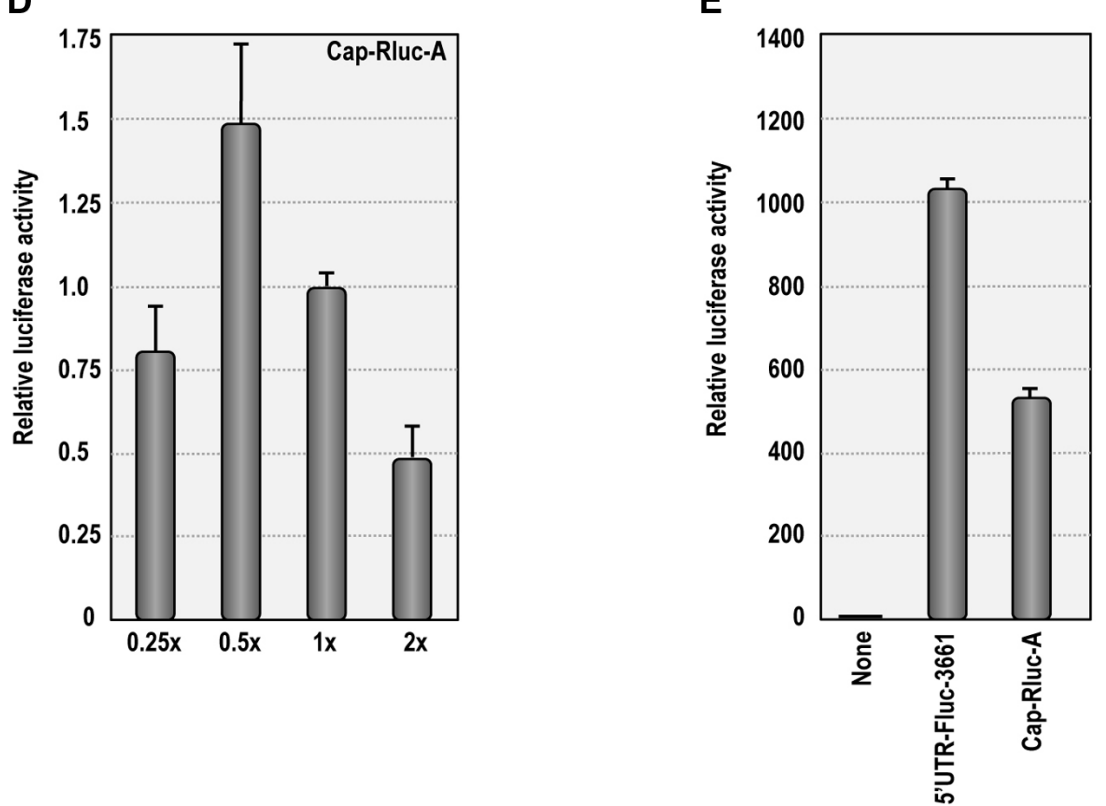

FIGURE 3 | Salt-washed plant ribosomes support cap-dependent and cap-independent translation in ribosome-depleted WGL.

(A) Map of 5'UTR-Fluc-3661 and Cap-Rluc-A reporter constructs. 5'UTR-

Fluc-3661 contains the firefly luciferase ORF flanked by the TCV $5^{\prime}$ UTR and positions 3661-4054. Cap-Rluc-A contains a capped, polyadenylated renilla luciferase ORF. (B) In vitro translation of 3'UTR-Fluc-3661 using ribosome-depleted WGL supplemented with either WGL ribosomes or
Arabidopsis ribosomes or ribosomal subunits. None, no ribosomes added. (C) In vitro translation of $3^{\prime}$ UTR-Fluc-3661 using ribosome-depleted WGL supplemented with different concentrations of sw Arabidopsis ribosomes. (D) Translation of Cap-Rluc-A using different concentrations of sw Arabidopsis ribosomes. (E) Comparison of cap-dependent (Cap-Rluc-A) and cap-independent (5'UTR-Fluc-3661) translation using 0.5 $\times$ sw Arabidopsis ribosomes. 
between the $5^{\prime}$ UTR and $3^{\prime}$ region of TCV (Stupina et al., 2008; Figure $3 \mathbf{A}$ ). In the absence of added ribosomes, translation using ribosome-depleted WGL remained at background levels (Figure 3B). When the reaction was reconstituted with ribosomes pelleted from WGL $(\sim 1 \times$ concentration $)$, translation of $5^{\prime} \mathrm{UTR}$ Fluc-3661 increased by $1.7 \times 10^{5}$-fold (Figure 3B). When 1 st spin or sw Arabidopsis ribosomes were used at the same concentration to supplement the depleted WGL, translation of 5'UTR-Fluc-3661 increased by 340 -fold or 1200 -fold over background, respectively. Translation of 5'UTR-Fluc-3661 was maximal when sw ribosomes were added at a concentration of $0.5 \times$ (Figure $3 \mathrm{C}$ ). The reduced level of translation resulting from supplemented Arabidopsis ribosomes compared with supplemented WGL ribosomes may have resulted from depletion of factors needed for translation when the WGL was subjected to ultracentrifugation to remove ribosomes. Alternatively, translation may be enhanced when both ribosomes and translation factors are derived from the same plant. Increased translation by Arabidopsis sw ribosomes over non-washed ribosomes suggests that salt-washing removes interfering tRNAs that might initially compete with the TCV TSS.

Supplementing ribosome-depleted WGL with 40S subunits $(1 \times)$ did not result in detectable translation over background levels. Addition of $60 \mathrm{~S}$ subunits $(1 \times)$ stimulated translation by 40-fold over background levels, possibly due to residual 80S subunits (Figure 3B). Interestingly, addition of $40 \mathrm{~S}$ and $60 \mathrm{~S}$ subunits eliminated the 60S-induced translational stimulation, suggesting that purified $40 \mathrm{~S}$ subunits compete with the residual $80 \mathrm{~S}$ ribosomes during translation. It is not known why combined $40 \mathrm{~S}$ and $60 \mathrm{~S}$ subunits were unable to complement the ribosome-depleted extracts.

Salt-washed Arabidopsis ribosomes were also tested for their ability to support cap-dependent translation. Similar to $5^{\prime}$ UTRFluc-3661, translation of Cap-Rluc-A reached maximal levels using $0.5 \times$ sw ribosomes, producing a 530 -fold enhancement over background levels (Figures 3D,E). This result demonstrates that sw plant ribosomes are functional in ribosome-depleted WGL and can support both cap-dependent and cap-independent translation.

\section{SALT-WASHED PLANT 8OS RIBOSOMES ASSOCIATE MORE EFFICIENTLY WITH VIRAL TSS COMPARED WITH YEAST 80S RIBOSOMES}

The TCV TSS binds to $80 \mathrm{~S}$ and 60S ribosomes and binding is important for translation (Stupina et al., 2008). Using filterbinding assays, the $K_{\mathrm{d}}$ for TSS binding to yeast $80 \mathrm{~S}$ ribosomes was $0.45 \mathrm{mM}$, and binding was slightly enhanced for $60 \mathrm{~S}$ subunits $(0.34 \mathrm{mM})$. Binding to $40 \mathrm{~S}$ subunits was non-specific (Stupina et al., 2008). To determine the $K_{\mathrm{d}}$ for TSS binding to Arabidopsis $80 \mathrm{~S}$ ribosomes, similar filter-binding assays were conducted. The TCV TSS associated with yeast ribosomes with a $K_{\mathrm{d}}$ similar to that previously published $(0.55 \mathrm{mM}$; Figure $4 \mathrm{~A})$, and plant ribosomes with a very similar $K_{\mathrm{d}}(0.42 \mathrm{mM}$; Figure 4B). However, only $\sim 10 \%$ of yeast ribosomes interacted with TCV TSS, whereas at least $30 \%$ of the plant ribosomes associated with the TSS.

A recent report from our laboratory (Gao et al., 2012) provides additional analysis on the association of Arabidopsis sw ribosomes and their individual subunits with the TCV TSS and a second TSS located in the $3^{\prime}$ UTR of Pea enation mosaic virus (PEMV). This PEMV TSS, unlike the TCV TSS, also participates in a longdistance kissing-loop ( $\mathrm{kl}$ ) interaction with $5^{\prime}$ proximal sequences and is therefore known as a kl-TSS. As previously reported for yeast ribosomal subunits (Stupina et al., 2008), the TCV TSS bound specifically to Arabidopsis $60 \mathrm{~S}$ subunits $\left(K_{\mathrm{d}}=0.23 \mathrm{mM}\right)$ and nonspecifically to Arabidopsis $40 \mathrm{~S}$ subunits (Gao et al., 2012). Similar to the TCV TSS, the PEMV kl-TSS associated with plant ribosomes with a threefold enhanced efficiency compared with yeast ribosomes (Gao et al., 2012). Interestingly, unlike the TCV TSS, the PEMV kl-TSS interacted specifically with both $40 \mathrm{~S}$ and $60 \mathrm{~S}$ subunits from Arabidopsis.

In conclusion, we have developed a simple, efficient protocol for isolation of plant ribosomes that produces ribosomes of high yield and quality. Our results suggest that plant RNA viruses
A

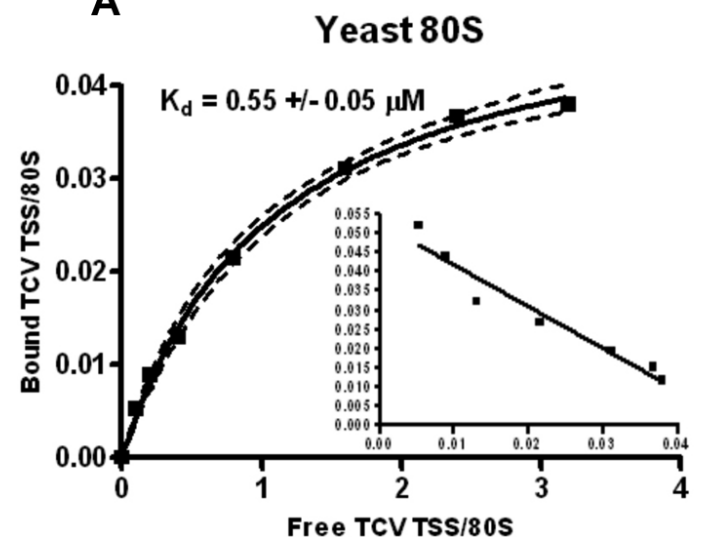

FIGURE 4 | Plant ribosomes associate with the TCVTSS at higher efficiency compared with yeast ribosomes. One to $60 \mathrm{pmol}$ of $\left[{ }^{32} \mathrm{P}\right] 5^{\prime}$-end labeled TSS were combined with $15 \mathrm{pmol}$ of sw yeast ribosomes (A) or sw plant ribosomes (B). $Y$-axis denotes the fraction of TSS bound per ribosome.

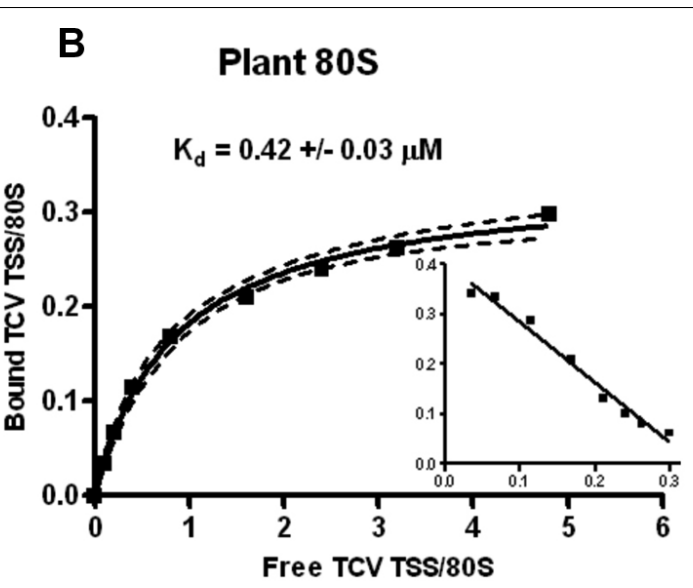

$X$-axis indicates the ratio of input (free) TSS to ribosomes. Scatchard plots are included for each saturation curve. To generate a saturation curve and to calculate $K_{d}$ values, each filter-binding experiment was conducted in triplicate. 
have evolved their translational cis-elements to maximize specific association with plant translation factors and that studies on cap-independent ribosome entry using plant mRNAs should use plant-derived ribosomes. We are hopeful that this method will be useful in further research into cap-independent translation mechanisms in plant viruses.

\section{REFERENCES}

Davies, E., and Larkins, B. A. (1973). Polyribosomes from peas: II. Polyribosome metabolism during normal and hormone-induced growth. Plant Physiol. 52, 339-345. doi: 10.1104/ pp.52.4.339

Gao, F., Kasprzak, W., Stupina, V. A., Shapiro, B. A., and Simon, A. E. (2012). PEMV ribosome-binding $3^{\prime}$ translational enhancer has a $\mathrm{T}$ shaped structure and engages in a long distance RNA-RNA interaction. J. Virol. 86, 9828-9842. doi: 10.1128/JVI.00677-12

Hara-Nishimura, I., and Hatsugai, N. (2011). The role of vacuole in plant cell death. Cell Death Differ. 18, 1298-1304. doi: 10.1038/cdd.2011.70

Key, J. L., Lin, C. Y., and Chen, Y. M. (1981). Heat-shock proteins of higher plants. Proc. Natl. Acad. Sci. U.S.A. 78, 3526-3530. doi: 10.1073/ pnas.78.6.3526

Komoda, K., Naito, S., and Ishikawa, M. (2004). Replication of plant RNA virus genomes in a cell-free extract of evacuolated plant protoplasts. Proc. Natl. Acad. Sci. U.S.A. 101, 1863-1867. doi: 10.1073/pnas.0307 131101

Lax, S. R., Lauer, S. J., Browning, K. S., and Ravel, J. M. (1986). Purification and properties of protein synthesis initiation and elongation factors from wheat germ. Methods Enzymol. 118, 109128. doi: 10.1016/0076-6879(86) 18068-2

Leaver, C. J., and Dyer, J. A. (1974). Caution in interpretation of plant ribosome studies. Biochem. J. 144, $165-167$.

Leshin, J. A., Heselpoth, R., Belew, A. B., and Dinman, J. D. (2011). High throughput structural analysis of yeast ribosomes using hSHAPE. RNA Biol. 8, 478-487. doi: 10.4161/rna. 8.3 .14453

MacIntosh, G. C., and Bassham, D. C. (2011). The connection between ribophagy, autophagy and ribosomal RNA decay. Autophagy 7, 662-663. doi: 10.4161/auto.7.6.15447

Malys, N., and McCarthy, J. E. G. (2011). Translation initiation: variations in the mechanism can be anticipated. Cell Mol. Life Sci. 68, 991-1003. doi: 10.1007/s00018-010-0588-z

McCormack, J. C., and Simon, A. E. (2005). "Callus cultures of Arabidopsis," in Current Protocols in Microbiology, Vol. 16D.1.1, eds R. Coico, T. Kowalik, J. Quarles, B. Stevenson, and R. Taylor (Hoboken: John Wiley and Sons, Inc).

McCormack, J. C., Yuan, X., Yingling, Y. G., Kasprzak, W., Zamora, R. E., Shapiro, B. A., et al. (2008). Structural domains

\section{ACKNOWLEDGMENTS}

This work was supported by grants from the U.S. Public Health Service (GM 061515-05A2/G120CD and GM 061515-07S1) and NSF (MCB 1157906) to Anne E. Simon. The authors would like to acknowledge Arturas Meskauskas and Micki Kuhlmann for establishing the procedure for WGL depletion.

within the $3^{\prime}$ untranslated region of Turnip crinkle virus. J. Virol. 82, 8706-8720. doi: $10.1128 /$ JVI. 00416-08

Meskauskas, A., Petrov, A. N., and Dinman, J. D. (2005). Identification of functionally important amino acids of ribosomal protein L3 by saturation mutagenesis. Mol Cell. Biol. 25, 10863-10874. doi: 10.1128/MCB.25.24.10863-10874. 2005

Mustroph, A., Juntawong, P., and Bailey-Serres, J. (2009). Isolation of plant polysomal mRNA by differential centrifugation and ribosome immunopurification methods. Methods Mol. Biol. 553, 109126. doi: 10.1007/978-1-60327563-7_6

Mustroph, A., Zanetti, M. E., Girke, T., and Bailey-Serres, J. (2013). Isolation and analysis of mRNAs from specific cell types of plants by ribosome immunopurification. Methods $\mathrm{Mol}$. Biol. 959, 277-302. doi: 10.1007/9781-62703-221-6_19

Simon, A. E., and Miller, W. A. (2013) $3^{\prime}$ Cap-independent translation enhancers of plant viruses. Annu. Rev. Microbiol. 67, 21-42. doi: 10.1146/ annurev-micro-092412-155609

Stupina, V. A., Meskauskas, A., McCormack, J. C., Yingling, Y. G., Shapiro, B. A., Dinman, J. D., et al. (2008). The $3^{\prime}$ proximal translational enhancer of Turnip crinkle virus binds to $60 \mathrm{~S}$ ribosomal subunits. RNA 14, 2379-2393. doi: 10.1261/rna. 1227808

Conflict of Interest Statement: The authors declare that the research was conducted in the absence of any commercial or financial relationships that could be construed as a potential conflict of interest.

Received: 03 April 2013; accepted: 02 July 2013; published online: 22 July 2013.

Citation: Stupina VA and Simon AE (2013) Preparation of biologically active Arabidopsis ribosomes and comparison with yeast ribosomes for binding to a tRNA-mimic that enhances translation of plant plus-strand RNA viruses. Front. Plant Sci. 4:271. doi: 10.3389/fpls.2013. 00271

This article was submitted to Frontiers in Virology, a specialty of Frontiers in Plant Science.

Copyright (c) 2013 Stupina and Simon. This is an open-access article distributed under the terms of the Creative Commons Attribution License, which permits use, distribution and reproduction in other forums, provided the original authors and source are credited and subject to any copyright notices concerning any thirdparty graphics etc. 